\title{
Legal Study On The Protection Of Children In Social Network: Special Reference To Indian Law
}

\author{
R. Kesavamoorthy \\ ${ }^{I}$ (Research Scholar, Dr. Ambedkar Government Law College, Pondicherry University, India)
}

\begin{abstract}
Now a day cyberspace is the place where children grow and learn, it is the duty of the every regulator to secure the children in the cyberspace. Privacy and security are the great concern while using social networking. Children are worst affected by the ill-practice of social networking. It is need of the hour to look into the legal aspects of the social networking and the child. Protecting the child from the cyber predators is one of the key concerns in India. This article throws light on the offenses committed to the child in the virtual space. It embarks upon various legal aspects related to the child and the use of social networking. This paper meticulously analyzes the lacunae in the legal framework and also brings out the problem solving solutions.
\end{abstract}

Keywords: child, law, privacy, protection, social networking, India

\section{Introduction}

Social networking is an online platform that facilitates building of social connections or social relationship among people. Online community is also a social network but it is broader than that of the social networking. While, an online community includes many members like a group, social networking is individual centered. The later allows users to share ideas, activities, events, interests and personal information within their individual network. Having a very long history, it started from the offline communities in the ancient period who met once in every day evening and discussed the issues, express the interests, chatting etc. The potential invention of computer and technologies created a gap among people and given a new platform to meet and chat. It is nothing but gradual growth of older technologies like Usenet and bulletin board services. These technologies only allow the user to communicate with text. For many reasons, this old technology do not fit into the new platform of web based technology. So the new technology has given birth to social networking. So the e-mail and text communication eventually have turned into profiling. The profiling technology improvised by the techies has led to many applications that allow the users to add information like photo, video, files etc. subsequently grouping has emerged. Now the social networking technology improving in many dimensions like geo tagging, tagging, geo social networking, interoperability between the social networks by OpenID and OpenSocial, real time web, location based, live feed, GPS live location etc.

India is the third biggest Facebook market which have nearly 4.98 crore users.[1] Semiocast, a social media monitoring tool, has rated India as the sixth highest user of Twitter. While globally the negative side of unmitigated use of social media is articulated, India has embraced social media without being too bothered about its possible hazards.[2] According to a Microsoft study on June 2012 that more than 50\% of the children in India using the net are either threatened or harassed online. The 'Global Youth Online Behaviour Survey' conducted by Microsoft, revealed that $53 \%$ of the surveyed children aged between eight and 17 in India admitted they were victims of cyber bullying.[3] A survey conducted by Tata Consultancy Services found that while 84 percent of the respondents had internet access at home, 85 percent used social networking site such as Facebook and 79 percent owned mobile phone.[4] Preferring entertainment on the move, 28 percent of the respondents said mobile phone was their favourite gadget. Eighty-eight percent respondents from metropolitan cities had a Facebook account while other platforms such as Orkut and India-based Apna Circle, Ibibo and Hi5 were more popular in small metros.[5]

Social psychology is a branch of psychology that deals with how groups behave and how it affects the individual members to which they belong. Now a day, it is obvious that most of us know how the group behaves, rest should be educated. The group it can behave crazy as though the laws are blind and it will never catch them but it is not the real scenario. One of the main objectives of this article is to explain how the children are vulnerable in the cyber space that gives them full freedom to take part in activities as they like with special reference to social networking. Law dealing with the social psychology includes matters like misrepresentation, fraud, cheating, defamation etc.

The main purpose of having a computer at home is to widen the knowledge curve of the child through internet. It places both opportunity for the self-directed learning and independence as well as the risk to the child. Lack of parental control is one of the zenith reasons for the negative use of internet by the children. Here, the negative use is all things that are opposite to the purpose for which the computer and internet connectivity 
introduced to the child. One-way the other children now a day have started using social networking. In particular, exposure of children to inappropriate content is common not only in the social networking but also available in the ambit of internet. While 56 per cent parents are concerned about their children in 13-17 age group being misguided online, 42 per cent parents of 4-8 year olds fear that their kids could be exposed to adult material.[6]

Innocent word searching in many popular search engines can lead to an unsuspecting child to numerous porn sites. There are so many words like toys, babe, boom, bum, dogs etc lead to porn site instead of their desired destination. There are some $30 \%$ of the porn sites using popular brands like Barbie, Disney, Popeye, Pokemon, power rangers, snow white and seven dwarfs etc in their websites. Therefore, it is easy for a child to come up with access to a porn site. Now the social networking also adds a source for the sexual content. Some profiles are targeted on adults to sell porn contents. Those profiles also very close to the children if they use social networking. Before exploring the legal aspects relating to this let's briefly discuss the impact on the child psychology.

Children addicted to the social networking without understanding the implications are falling victim. A Class 10 student stabbing his classmate in a central Delhi school, apparently miffed at the latter posting his photograph on Facebook[7]. Now, it is common among the school students to create a page on their teacher on a social networking site in order to make fun of him/her and abuse him/her. Children often imitate what the others doing. It is also possible that the child exposed to pornography may incite children to act out sexually against other children. In this case, child may have to face legal proceedings that eventually end in the rehabilitation center.

Child behavioral impact is the next big issue arise out of the use of social networking. Children at this age can be easily influenced by others like peer influences, celebrity influence and even some adult content influence. These influences can easily dilute the core moral value of the child. It is some time alarming situation for the whole society. The behavioral impact may cause syndromes like obesity, attention disorder, eating disorder, violence etc. They may lose the joy of moving with other people. So the relationships are at risk that most children have more online relationship than the real one. As mentioned above, they use different personality than that of the real one in the social networking profile and they always live in virtual imaginary world. This will reduce the capacity of the children to understand the pros and cons of the real world. Individualism by the social networking created a new style of life, a style where individuals come first. Individualism restrains the habit of understanding and accepting the relationship. With the increase in the uncensored use of social networking, kids are vulnerable to online fraud and aggressive marketing techniques as well.

Though internet and social network widen the learning curve, the improper use of the same can cause defective learning. For example, because of excessive use of abbreviations, children are not using grammar at all. This is a very serious problem for the non-English speaking countries like India. This habit is on increase because of excessive online chatting, commenting and posting etc. In addition to all the above threats, there are many other potential threats like cyber bullying, sexual predators, sexting, stalking, sexual harassment and exposure to inappropriate content.

\section{Legal Framework Relating To Social Networking In India}

There is wide gap existing between the Indian laws and the social networking. The legislature should go a long way to draft a legislation to tackle the problems of social networking. The Information Technology Act 2000, which is the only Act dealing with the cyber space, is silent about the definition of child, minor, age etc. It is irony that the issue of the age is not specified even in the Information Technology Act, indicating clear negligence on the part of the legislature in drafting the Information Technology Act. section 2 (1)(w) of the Information Technology Act defines intermediary as with respect to any particular electronic message means any person who on behalf of another person receives, stores or transmits that message or provides any service with respect to that message. Hence, it is that the social networking comes under the meaning of intermediary under the Information Technology Act.

The act or omission that amounts to offence in the cyber space will be punishable under the Indian Penal Code also. As the context and magnitude of the offence is different from the conventional crimes, the platform in which the offence is happening is itself different from conventional crimes. The cyber crimes are happening in a virtual world in the cyber platform and it's effects are in the real world. Thus, it needs a different approach. It is apparent from the various surveys conducted in India that the present legislations are not adequate to deal with cyber crimes against the child. So tackling these kinds of crimes needs totally a different approach that will never be fulfilled by the existing legislations. Information Technology Act itself has many lacunas. The offences defined in the IT Act, 2000 are by no means exhaustive. It does not cover various kinds of cyber crimes and Internet related crimes. Moreover, these crimes are mostly against the children. Such crimes are cyber stalking, cyber harassment, cyber bullying etc. 
The social networking sites should be governed by the law of the land in which it operates. In Feb 2012, the Delhi High Court ordered 22 social networking sites to remove the inflammatory content. The social networking sites offer get away with their liability by saying that they are bound by the US laws and are not amenable to the Indian law. This has happened not only in India but also to google in China and yahoo in France[8]. After a prolong request to pull out the inflammatory contents, facebook and google have removed the inflammatory contents from the Indian domain sites. Lack of cyber due diligence is one of the issues that should be addressed by the sound social networking policy in India. The Information Technology Act mandates the service providers to be due diligence of content that could be a threat for the security and integrity of the nation. In case if it affects any person, complaint can be lodged against the content available online. The websites are duty bound to remove the content within 36 hours from the Indian network. Failing to do so will attract penalties under the Information Technology Act.

\section{Age Of A Child}

Article 1 of the United Nation's Convention on the Rights of a child defines child as every human being below the age of 18 years unless, under the law of the land applicable to the child or majority is attained earlier. Thus, this Article grants discretion to the countries to determine the majority age. According to the Article 23 of the Constitution of India, children below the age of 13 years should not be employed to work in any factory, mine or engage in any other hazardous employment. To know the right child age have to look into the Indian Penal code (IPC). IPC puts criminal responsibility above seven years. Under section 82 of the IPC nothing is an offence which is done by the child under the age of seven. This is mainly because of the absence of mens rea. The age of the child is further raised to twelve years. Under section 83 offence committed by the child above the age of seven and under twelve, who has not attained sufficient maturity of understanding to judge of the nature and consequences of his conduct on that occasion is not punishable. But this section gives a wide discretion to the judiciary to decide whether the child is matured or not. In addition, section 90 of the IPC states as the consent given by the person who is under the age of twelve is not valid. Anyone who abetted the commission of suicide of child under the age of eighteen years will be punishable under section 305 of the IPC. Next important Act to look for the age of a child is Indian Contract Act, 1872. According to this Act, a person under the age of eighteen has no capacity to enter into a contract. The other Act that is closely related to this topic is Child Marriage Restriction Act, 1926. According to this Act a child means a male who has not completed the 21 years of age. In case of female who has not completed the age of 18 . The Juvenile Justice Act, 1960 states that a juvenile is a child who has not completed the age of 16 years in case of a boy if female she has not completed the age of 18 years. According to the Child Labour (Prohibition and Regulation) Act, 1966 the age is fixed as who has not completed his fourteen years of age. Factories Act, 1948 restricts a child below the age of fourteen to work in any factory.

\section{Contract Between The Service Provider And The Users}

Before discussing the issues relating to the contract between the parties in the social networking service provider, let's briefly introduce the nature of online contract. Most of the e-contracts are standard form of contracts i.e. legally binding agreement between two parties to do a certain thing, in which one party has all the bargaining power and uses it to write the contract primarily to his or her advantage.[9] One party has all the drafting power regarding terms and conditions of the contract, and the other party is placed in a take it or leave it position. The other party has no opportunity to negotiate the terms of the contract. Insurance policies, contract with government, service warranty etc are some examples of the standard form of contract. The contract between the social networking service provider and the user is also a contract of the same.

\section{Age matters}

Various social networking sites like facebook prescribes the minimum age to register as a user is 13 and it is a standard form of contract. Nevertheless, it is not a strict requirement. It leaves the option in the hands of the countries in which they are utilizing their service. Consumer Reports has found in its 2011 State of the Net Survey that More than 5 million children are in the age of 10 and under well below Facebook's minimum age of 13 use the service. Despite critics' concerns, the fact is that numbers of under-13s have already joined the network, by misrepresenting about their age while filling in the sign up form. According to Consumer Reports, out of the 20 million minors who actively use Facebook, 7.5 million are younger than 13, while more than five million are younger than 10.[10]

As discussed in the previous segment (Age of a child) there is no certainty among the various statutes in India regarding the age of a child. Anyone who wants to enter into the social networking site should accept the terms and conditions of the service provider. The terms and services is a standard form of contract it is also called as shrink-wrap or click next contract. Therefore, it is mandatory to look into the context of the Indian Contract Act for the valid age to enter into a contract. Under the Indian Contract Act anyone who has completed 
the age of 18 year can enter into a contract. However, the reality is different. In 2011 a survey conducted by global security technology firm McAfee in ten major cities across India revealed that that 62 per cent of affluent kids in the age group of 4-12 years have an e-mail ID, while 58 per cent of them have an account on social networking sites.[11] After all, more than half of the parents with 12 year olds said in a recent survey that their child already have an account and most are lied about their kid's age to help them open it.[12] Faking the age for the purpose of entering into a contract amounts to misrepresentation under section 18 of the Indian Contract Act. Also, the consent given by the child is not at all a valid consent and the contract is void ab initio. Therefore, the contract is not binding on the party. In such a case, the child is the victim all the time. Let's deal with what is misrepresentation to find out the consequences of the misrepresentation by child.

\section{Misrepresentation In Social Networking}

Section 18 of the Indian Contract Act defines misrepresentation as the person who making it may not warrant that it is not true. In addition, misrepresentation gives positive assertion. It misleads the other to gain an advantage. Misrepresentation in the real world is punishable under the Indian Penal Code. Misrepresentation is referring to a false statement of fact made by one party to another party, which has the effect of inducing that party into the contract. The personal space given by the social networking sites can be used to create personal profile that represents the user. Profile is a short biographical account of somebody. In other words a brief description that summarizes the characteristics of a person. Users can actually announce the world about his/her personality and characteristics through profile. Users should keep in mind that they are strictly responsible for whatever they post on their own profile. One's social networking personality may be slightly different from that of actual personality. Most social networking users do not even use their own image in profile. It may be by way of precaution but if they use some other or some other's photo, it can lead to legal complications like misrepresentation and copyright violation. Misrepresentation is referred in the Indian Penal Code as misconception of Fact under section 90 which states that consent given under fear of injury and under misconception of fact is not consent at all.

Users should bear in mind that misrepresentation of one's own identity is an offence under the Indian Penal Code. It is applicable to the virtual world too. For getting into facebook, a child can fake his/her age, and if the child caught in the eyes of Internet surveillance team set up by different NGOs and government organizations, the child may face legal procedures. In worst case, the child could be sent to re-habilitation centers too. If the parents or anyone major help them open an account on social networking sites it amounts to abetment of offence and the same can be punishable under section 109 of the IPC.

\section{Offence committed by a child}

\section{Offence And Child}

It is a very rare case. In addition, it is not punishable if an offence committed by a child. If a person, who is under the age of 18 years could be punishable under the Juvenile Justice Act, if he/she is in conflict with laws. Juvenile in conflict with law means a juvenile who is alleged to have committed an offence. If a child above seven years of age commits these offences like harassment, defamation etc., it has ill effect in future. It attracts the Juvenile Justice Act.

Furnishing false information attracts section 177 and misconception of fact under section 90. However, the child cannot be punishable under the IPC as it excludes the liability of a child from offence committed by them under section 82 (below the age of seven) and 83 (Who has not attained sufficient maturity of understanding to judge the nature of his act.) It is for the Juvenile Justice Board to decide whether he/she was aware of the nature and consequences of his/her act. If the Juvenile Justice Board decides this issue in the negative, he/she will immediately be discharged. If the Board decides positive then he/she may be sent to a Special Home for a period until he/she ceases to be a juvenile, or in the case of a juvenile over 17 years of age and below 18 years for a period not exceeding 2 years.

\section{Offence committed to a child}

Common offences against a child in the social networking are Cyber bullying, cyber stalking, sexting, molestation, trolling etc Cyber bullying actions that use information and communication technologies to support deliberate, repeated, and hostile behavior by an individual or group that is intended to harm another or others. Cyber bullying is when a child or group of children (under the age of 18) intentionally intimidate, offend, threaten or embarrass another child or group of children specifically through the use of information technology, such as a website or chat room on the Internet, a cellular telephone or another mobile device. The actions are deliberate, repeated, and hostile behavior intended to harm another. Cyber stalking is the use of the Internet or other electronic means to stalk or harass an individual, a group of individuals, or an organization. It may include the making of false accusations or statements of fact (as in defamation), monitoring, making threats, identity theft, damage to data or equipment, the solicitation of minors for sex, or gathering information that may be used 
to harass. Though cyber bullying and cyber stalking are very similar, there exists difference between them. The practice of cyber bullying is not limited to the children but in most of the cases the cyber stalking is against children. Common tactics used by the cyber stalkers are performed in public forums, social media or online information sites and are intended to threaten a victim. Cyber stalking is a weapon used to damage the reputation of the victim. Cyber stalking is mainly for revenge, hate or retribution. All cyber stalking are a form of cyber bullying, in other words cyber bullying is a genus while the cyber stalking is specie. Sexting is the act of sending sexually explicit messages or photographs, primarily between mobile phones.

Why talking so much about cyber bulling? This is one of the vital question that is to be answered before going into legal consequences. A new poll conducted by global research company Ipsos for Reuters News finds that one in ten parents online (12\%) around the world say that their child have experienced cyber bullying while one in four (26\%) say they know a child in their community who have experienced the same. Of those, a majority $(60 \%)$ say their children have experienced the harassing behavior on social networking sites like facebook. Three quarters (77\%) of world residents say cyber bullying needs special attention from parents and schools while a minority (23\%) think cyber bullying can be handled through existing anti-bullying measures. Cyber bullying in India can evenly be split between social networking sites (55\%) and online chat rooms (54\%). Three out of ten Indian children have faced cyber bullying.[13]

The sex offenders in the social networking are also called as Cyber sexual predator. Sexual predator is a person who s obtaining or trying to obtain sexual contact with another person in predatory manner. People who commit molestation, child sexual abuse, rape etc are commonly referred as sexual predators. He/she hunts for his prey. The way he adapts to hunt differs. If he adapts the internet to hunt for prey, then he is termed as cyber sexual predator. The predator comes to know the information of the child by means of the online chatting, online grooming, public profiles, mailing, messaging etc. About $75 \%$ of the children go online share personal information like family members, educational background, likes and dislikes etc. Sample survey revealed that 58 per cent of kids, half of them between 4-8 years, admitted to sharing their home address and 55 per cent of them sharing their contact details on the Internet. [14] This survey came with astonishing result that 32 per cent of the parents surveyed knew that their kids were sharing information online. 42 per cent of parents of 9-12 age group believed that their kids would have shared personal data such as home address, contact number and the city in which they reside with their virtual friends, strangers and the unknown. [15]

The predators use these details to get close to the child. Slowly starts indulging in sexual contact with the child. Usually threatening will happen using some secret information that is shared in the child profile. Predator uses porn contents in form of images or videos to blur the child that others are doing it so there is no wrong in doing. If the child is not willing to take part in the course, predator starts harassing them.

There are various stringent provisions in the IPC to deal with the cyber sexual predators. Section 292 and 293 of the IPC deal with the selling, distribution, publishing or circulating of obscene material such as books, magazines, drawings, paintings, etc. The commission of such acts amount to an offence punishable with imprisonment which may extend to 3 years and fine; any subsequent convictions for the same offence is punishable with imprisonment for a term which may extend to 7 years and fine. The sad thing is that in India law does not have any distinct provision with regards to child pornography. Continuous harassment leads the child to suicide and it is punishable under section 305 (Abetment of suicide) of the IPC. It deal with the abetment of suicide of a person under 18 years of age which is punishable with death or imprisonment for life or imprisonment for a term not exceeding 10 years and fine. Abetment is the instigating of a person to commit an act or intentionally aiding a person to commit an act.

Torturing a child will lead them to unnecessary mental illness. Continuous torture will result in mentally retarded. If a person having actual charge of the children commits it, it is punishable under the Juvenile Justice [Care and Protection of Children] Act 2000. Any person having actual charge of or control over a child, assaults, abandons, exposes or neglects the child in a manner likely to cause the child unnecessary mental or physical suffering will be punishable with imprisonment which may extend to 1 year and fine.

\section{Conclusion}

Apparently, children are not only the guinea big to the social networking. Many times, adults also fall prey to the social networking. Adult falling prey to social networking is always a different issue than that of a child because children who are more vulnerable than the grown up. The parental control absence is one of the main threat to the children. McAfee India director V. Krishnapur said in an interview, "Only 25 per cent of parents trust their children online without monitoring them, though the trust levels increase as their kids get older. A healthy 73 per cent parents counseled their children on the do's and don'ts of using Internet." Most of the children are constructing a barrier between their personal life and parents. Many social networking websites provide user with a choice of who can view the profile. In particular, sexual predators are working round the clock to get victims. Parents sometimes abuse the child by way of addiction to the games hosted by social networking site like Facebook and neglect their children causing a child to die from starvation.[16] Child 
pornography is another one giant crime that is committed all over the world offline. In 2010 it is a largest criminal case against the children in a social networking site with hundreds of members dismantled by law enforcement.[17] Acknowledging the reality, Facebook says that it will provide a legitimate on-ramp that would allow a safer, more appropriate experience for the youngest users. [18]

Nevertheless, the social networking sites operate in different countries with different countries having different age for child. Though the social networking sites provide minimum age to enter into the service provided by them, they cannot enforce them. Also the verification of the age is absent that anyone can create an account, there is nothing preventive in it so millions of children under the age limit is using the social networking sites. In India above 18 is a age for a person to use the social networking. A 2008 panel concluded that technological fixes such as age verification and scans are relatively ineffective means of apprehending online predation.[19] Every social networking site contains terms of service which provides age limit for its users and others are restricted from using the site. If anyone creating the account is more likely signing a contract, if anyone creates an account below the prescribed age limit $\mathrm{s} / \mathrm{he}$ is violating and it amount to illegal or misuse of service provided by the website and obviously attracts criminal action against the violator.

The most important thing is that we need new policies on social networking. Lack of policies render the crime in social networking undetectable. The conventional laws are not adequate to tackle the frequently changing cyber crime. Mostly the identity of the offender in cyber crime is very hard to identify. Tracking the cyber criminals need experts in that field. In addition, those experts should work in consonance with the government authorities. In India, the present enforcing authority is seldom skilled. The nature of the crime against the child in cyberspace is very novel and so it needs an independent expertise enforcing authority to implement the law. Mostly these crimes are extra-territorial in nature and pose a big challenge to the enforcing authorities. Many times tracking an offence needs cooperation of another country. In such situations, India needs to sign memorandum of understanding to ease the process of the investigation.

[1] According to the social media company Socialbakers.

[2] http://www.dnaindia.com/lifestyle/report cyberbullying-social-media-s-darker-side 1712080 (Accessed on 07-07-2013)

[3] For more detailed result please visit : http://www.microsoft.com/security/resources/research.aspx (Accessed on 12-07-2013)

[4] 'Tata Consultancy GenY Survey 2011-2012' of nearly 12,300 high school students across 12 Indian cities.

[5] http://www.thaindian.com/newsportal/uncategorized/more-indian-teens-using-networking-sites-to-communicate_100619826.html (Accessed on 22-06-2013)

[6] http://gadgets.ndtv.com/internet/news/indian-parents-wary-of-kids-getting-hooked-online-survey-225908(Accessed on 22-06-2013)

[7] articles.timesofindia.indiatimes.com/2012-05-18/computing/31764543_1_networking-sites-delhi-school-social-media(Accessed on 09-07-2013)

[8] to pull out the links to Nazi sites

[9] http://legal-dictionary.thefreedictionary.com/Standard +form+contract(Accessed on 07-07-2013)

[10] For full report : http://news.consumerreports.org/electronics/2011/05/five-million-facebook-users-are-10-or-younger.html(Accessed on 11-08-2013)

[11] http://gadgets.ndtv.com/internet/news/indian-parents-wary-of-kids-getting-hooked-online-survey-225908(Accessed on 02-08-2013) [12] Peggy Orenstein, Let's not Update Preteens to Social Media, Indian Express, Jun12, 2012. P8.

[13] Ipsos surveyed a total of 18,687 citizens in 24 countries via online survey methodology. For more Details in this survey please visit: http://www.ipsos-na.com/news-polls/pressrelease.aspx?id=5462(Accessed on 24-07-2013)

[14] The sample survey, titled "How safe are Indian kids online?" was conducted by the market research arm Synovate of Aegis Group plc across 10 cities - Ahmadabad, Bangalore, Chennai, Cochin, Hyderabad, Kolkata, Ludhiana, Mumbai, New Delhi and Pune, covering 500 children and 496 parents.

[15] http://gadgets.ndtv.com/internet/news/indian-parents-wary-of-kids-getting-hooked-online-survey-225908(Accessed on 24-07-2013)

[16] http://www.guardian.co.uk/world/2010/mar/05/korean-girl-starved-online-game(Accessed on 24-07-2013)

[17] http://www.huffingtonpost.com/2010/05/27/child-porn-social-network_n_591663.html(Accessed on 24-07-2013)

[18] Peggy Orenstein, let's not update preteen to social media, Indian Express. Jun 12, 2012. Page8

[19] nternet Safety Technical Task Force, Final Report of the Internet Safety Technical Task Force to the Multi-State Working Group on Social Networking of State Attorneys General of the United States. 2008 (published 31 december 2008); Mangu-Ward, Katherine (May 2009). "MySpace = Safe Space" http://cyber.law.harvard.edu/pubrelease/isttf/ (Accessed on 25-07-2013) 